\title{
Effect of radiofrequency radiation from Wi-Fi devices on mercury release from amalgam restorations
}

\author{
Maryam Paknahad ${ }^{1}$, S. M. J. Mortazavi ${ }^{2,3^{*}}$ D, Shoaleh Shahidi ${ }^{1,4}$, Ghazal Mortazavi ${ }^{3}$ and Masoud Haghani ${ }^{3}$
}

\begin{abstract}
Background: Dental amalgam is composed of approximately 50\% elemental mercury. Despite concerns over the toxicity of mercury, amalgam is still the most widely used restorative material. Wi-Fi is a rapidly using local area wireless computer networking technology. To the best of our knowledge, this is the first study that evaluates the effect of exposure to Wi-Fi signals on mercury release from amalgam restorations.

Methods: Standard class V cavities were prepared on the buccal surfaces of 20 non-carious extracted human premolars. The teeth were randomly divided into 2 groups $(n=10)$. The control group was stored in nonenvironment. The specimens in the experimental groups were exposed to a radiofrequency radiation emitted from standard Wi Fi devices at $2.4 \mathrm{GHz}$ for $20 \mathrm{~min}$. The distance between the Wi-Fi router and samples was $30 \mathrm{~cm}$ and the router was exchanging data with a laptop computer that was placed $20 \mathrm{~m}$ away from the router.

The concentration of mercury in the artificial saliva in the groups was evaluated by using a cold-vapor atomic absorption Mercury Analyzer System. The independent $t$ test was used to evaluate any significant differences in mercury release between the two groups.
\end{abstract}

Results: The mean $( \pm \mathrm{SD})$ concentration of mercury in the artificial saliva of the Wi-Fi exposed teeth samples was 0. $056 \pm .025 \mathrm{mg} / \mathrm{L}$, while it was only $0.026 \pm .008 \mathrm{mg} / \mathrm{L}$ in the non-exposed control samples. This difference was statistically significant $(P=0.009)$.

Conclusion: Exposure of patients with amalgam restorations to radiofrequency radiation emitted from conventional Wi-Fi devices can increase mercury release from amalgam restorations.

Keywords: Amalgam, Wi-Fi, Mercury release, Radiofrequency, Electromagnetic fields

\section{Background}

Dental amalgam is still the most widely used restorative material in the last 150 years especially in posterior teeth because of its high mechanical strength, durability, ease of manipulation, and low cost [1-5]. Dental amalgam is an alloy comprised of $50 \%$ elemental mercury and a mixture of other metals such as silver, tin, copper, and sometimes palladium, indium and zinc [6-8]. Dental

\footnotetext{
*Correspondence: mmortazavi@sums.ac.ir; mortazavismj@gmail.com; http://home.sums.ac.ir/ mmortazavi; http://crrs.sums.ac.ir

${ }^{2}$ Medical Physics and Medical Engineering Department, School of Medicine,

Shiraz University of Medical Sciences, Imam Hossein Square, 7134845794

Shiraz, Iran

${ }^{3}$ Ionizing and Non-ionizing Radiation Protection Research Center (INIRPRC),

Shiraz University of Medical Sciences, Shiraz, Iran

Full list of author information is available at the end of the article
}

amalgam is considered as the primary source of continuous mercury exposure in general population [1, 9-11]. Mercury is a toxic element which can damage various organs such as central nervous system, renal, respiratory and hematologic systems [12,13]. Because of the mercury toxicity, the use of mercury has been banned in some European countries [14]. The amount of mercury which releases from amalgam restorations depends on several factors such as number and size of the fillings, composition of amalgam, any other factors that causes load over the restorations like tooth brushing, chewing habits,and bruxism $[8,15]$.

Wi-Fi is a local area wireless computer networking technology and has been used drastically in houses and public places such as schools and hospitals during recent 
years [16]. It allows electronic devices such as personal computers, video-game consoles, smart phones, digital cameras and tablet computers to network using Institute of Electrical and Electronics Engineers (IEEE) 802.11 standards. These standards mainly use the 2.5 gigahertz $(12 \mathrm{~cm})$ UHF and 5 gigahertz $(6 \mathrm{~cm})$ SHF ISM radio bands [17]. The lower cost and easier deployment of these devices than wired computer networks lead to rapidly increase of Wi-Fi devices [18]. However, this also raised great public concern about the potential adverse effects of exposure to electromagnetic fields (EMFs) emitted from these devices [19].

The adverse health impacts associated to exposure to some common sources of electromagnetic fields including laptop computers, mobile phones, MRI and mobile phone jammers have been evaluated by our laboratory in our previous investigations [20-24]. To the best of our knowledge, this is the first study that evaluates the effect of exposure to Wi-Fi signals on mercury release from amalgam restorations.

\section{Methods}

\section{Teeth samples}

This study was approved by the Ethics Committee of Shiraz University of Medical Sciences. Twenty noncarious premolar teeth which were extracted as a part of orthodontic treatment were used in this study. The teeth were stored in isotonic saline solution for not longer than 3 months after surface debridement. The teeth were randomly divided into 2 groups of exposure and control, each containing 10 teeth.

\section{Amalgam fillings}

Standard class V cavities (3mm length, $2 \mathrm{~mm}$ depth and $5 \mathrm{~mm}$ width) were prepared on the buccal surface using carbide burs (SS White Burs, Lakewood, NJ) and a high speed turbine under water spray. The cavities were restored with Cinalux (non-gama-2, spherical amalgam, Faghihi Dental, Tehran, Iran) amalgam. The amalgams were triturated according to manufacturers' directions, and then they were condensed incrementally towards the cavity walls. All the procedures for restoration of the cavities were performed by the same clinician. The restored teeth were plunged in saline solution at $37^{\circ} \mathrm{C}$ for 14 days because as it was discussed by Muller Miny et al., the mercury release from amalgam restorations decrease gradually to a constant level 14 days after the filling [25]. Following that and before exposing the teeth, samples were poured into plastic tubes filled with artificial saliva. The thickness of the artificial saliva covered over teeth samples was $1.5 \mathrm{~cm}$ to mimic soft tissue.

\section{Wi-Fi exposure}

The exposure group was exposed to radiofrequency radiation emitted from standard Wi-Fi devices at 2.4 $\mathrm{GHz}$ for $20 \mathrm{~min}$. The distance between the Wi-Fi router (D-Link, China) and samples was $30 \mathrm{~cm}$ and the router was exchanging data with a laptop computer that was placed $20 \mathrm{~m}$ away from the router. The control group was kept outside the experiment room. The geometry used for exposure is shown in Fig. 1.

\section{Mercury measurement}

Based on our previous experiments, it was clearly revealed that the pre-exposure mercury concentration in the saliva containing teeth samples with exactly identical fillings (the same cavities and amalgam type), was the same for all samples (the differences were not statistically significant). Therfore, the mercury levels were measured in the artificial saliva after exposure by cold vapor atomic absorption spectrometry (CVAAS; Analytical Jena, vario 6, Germany).

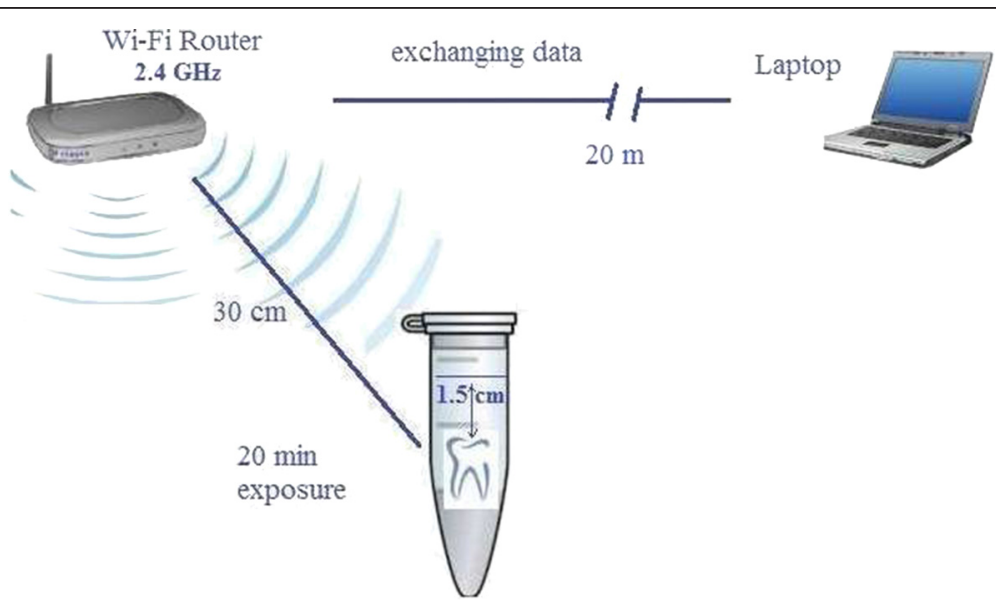

Fig. 1 The geometry used for exposure of the teeth samples 


\section{Statistical analysis}

The data were statistically analyzed using SPSS version 16.0 (SPSS Inc., Chicago, IL) (http://www-01.ibm.com/ software/analytics/ spss). The independent $t$ test was used to compare the level of mercury release in the exposure and control groups to identify any statistically significant differences. $P$ value $<0.05$ was considered significant.

\section{Results}

Descriptive statistics were presented as the mean, standard deviation, minimum and maximum in Table 1 . The mean $( \pm \mathrm{SD})$ concentration of mercury in the artificial saliva of the Wi-Fi exposed group was $0.056 \pm .025 \mathrm{mg} /$ $\mathrm{L}$, while it was only $0.026 \pm .008 \mathrm{mg} / \mathrm{L}$ in the nonexposed control samples. Therefore, the mean concentration of mercury in the Wi-Fi group was about twice of the control group. The observed difference in the concentration of mercury in the artificial saliva of the exposure and control group was statistically significant $(P=0.009)$.

\section{Discussion}

Public concern about the possible adverse health effects of using Wi-Fi technology is increasing because of the widespread use of wireless communication systems [19]. In the present study, it was concluded that radiofrequency radiation emitted from Wi-Fi devices significantly increased mercury release from amalgam restorations.

Mortazavi and Mortazavi have recently reviewed the published reports on the increased release of mercury from dental amalgam fillings after exposure to different sources of electromagnetic fields (e.g. MRI, mobile phones) [26]. These studies are summarized in Table 2. The first report on the role of exposure to MRI or microwave radiation emitted by mobile phones in increasing the release of mercury from dental amalgam filling was published by Mortazavi et al. in 2008 [27]. To overcome the limitations of their previous study, Mortazavi and his colleagues have recently studied the effects of stronger magnetic fields $(1.5 \mathrm{~T}$ in their recent study vs. $0.25 \mathrm{~T}$ in their previous report). This study confirmed the previous findings and provided further support for increased release of mercury from dental amalgam fillings after MR imaging [28].

It should be noted that the results obtained in the studies performed on the role of exposure to

Table 1 The mean, standard deviation, minimum and maximum of the mercury release in the two groups

\begin{tabular}{llll}
\hline Mercury release $(\mathrm{mg} / \mathrm{L})$ & Group & (P-value) \\
\cline { 2 - 3 } & Control & Wi-Fi & \\
\hline Mean \pm SD & $0.026 \pm .008$ & $0.056 \pm .025$ & 0.009 \\
(Range: $\min$-max) & $(0.016-0.039)$ & $(0.020-0.100)$ & \\
\hline
\end{tabular}

electromagnetic fields in magnetic resonance imaging on the microleakage of amalgam are strongly in line with the findings of Mortazavi et al. [29, 30]. To the best of our knowledge, our current study is the first study that investigates the effect of radiofrequency radiation emitted by Wi-Fi routers on mercury release from amalgam restorations.

Mercury is a toxic element which has adverse biological effects even at low doses [31]. Therefore, it seems to be necessary to apply a sensitive and reliable analytical technique to determine mercury content. Various analytical techniques has been used previously for the determination of mercury in environmental and biological samples such as cold vapor atomic absorption spectrometry (CVAAS), cold vapor fluorescence spectrometry (CVAFS), inductively coupled plasma optical emission spectrometry (ICP OES), electrothermal atomic absorption spectrometry (ET AAS), neutron activation analysis, mass spectrometry, anodic stripping voltammetry, and cold vapor inductively coupled plasma mass spectrometry (CV ICP-MS) [32-35]. This study employed CVAAS method for measuring mercury released from dental amalgam. Because CVAAS is the most widely technique used in previous studies for detecting this element at low concentrations due to its high sensitivity and selectivity and because of its low cost $[36,37]$.

To improve the outcome of the west possible mercury release, we did not polish the cavities after restoration, because according to Ferracane et al. greater amounts of mercury would release from unpolished than polished surfaces [38].

Although the adverse health effects of the exposure to radiofrequency radiation emitted by Wi-Fi routers on some challenging phenomena such as human reproductive capabilities is well documented by some researchers around the world [39, 40], as far as we know, there is no report on the role of Wi-Fi radiation on the release of mercury from amalgam restorations. The mercury release from dental amalgam into saliva has been evaluated in previous studies both in vitro and in vivo conditions [25, 31, 41-43]. One of the limitation of in vivo studies, as Mortazavi et al. discussed in their study, was that the participants were referred by their own physicians and the investigators did not have control over the number and surface of amalgam fillings [41]. However, in our in vitro study, we could control these factors by using identical class $\mathrm{V}$ fillings with the same dimensions through application of a template during cavity preparations since the mercury exposure correlates significantly to the number and surface of fillings $[8,15]$. We also could control some other confounding factors which differ inter individually such as chewing 
Table 2 Comparison of the findings of current study with other studies performed either on mercury release or amalgam microleakage after exposure to electromagnetic fields

\begin{tabular}{|c|c|c|c|c|}
\hline Radiation source & Endpoint & Methods & Basic finding & Reference \\
\hline Mobile Phone & Release of Mercury & $\begin{array}{l}\text { Urine samples were collected from } 14 \\
\text { female students }\end{array}$ & $\begin{array}{l}\text { A statistically significant }(p<0.05) \text { higher concentration } \\
\text { of mercury was observed in the students who used } \\
\text { mobile phones. }\end{array}$ & Mortazavi et al. [27] \\
\hline MRI $(0.23 \mathrm{~T})$ & Release of Mercury & Stimulated saliva collected in 30 persons & $\begin{array}{l}\text { Elevated urinary mercury concentration in the exposed } \\
\text { group }\end{array}$ & Mortazavi et al. [27] \\
\hline MRI (1.5 T) & Release of Mercury & $\begin{array}{l}\text { Urinary concentrations of mercury in the } \\
\text { MRI exposed and control subjects }\end{array}$ & $\begin{array}{l}\text { The urinary mercury in the exposed group, } 72 \mathrm{~h} \text { after } \\
\text { MRI ( } 96 \mathrm{~h} \text { after restoration),was significantly higher } \\
(p=0.046) \text {. }\end{array}$ & Mortazavi et al. [28] \\
\hline X-ray & Release of Mercury & $\begin{array}{l}\text { Teeth samples were exposed to X-rays in } \\
\text { a soft tissue-equivalent material }\end{array}$ & $\begin{array}{l}\text { A significant increase in mercury was observed in the } \\
\text { X-ray-exposed group }(p \leq 0.05) \text {. }\end{array}$ & Kursun et al. [42] \\
\hline MRI & Release of Mercury & $\begin{array}{l}\text { Teeth samples were exposed to MRI in a } \\
\text { soft tissue-equivalent material }\end{array}$ & $\begin{array}{l}\text { No significant difference was found in the } \\
\text { MRl-exposed group. }\end{array}$ & Kursun et al. [42] \\
\hline MRI (3 T) & Microleakage of amalgam & $\begin{array}{l}60 \text { extracted teeth divided into experimental } \\
\text { and control groups exposed/shamexposed } \\
\text { to a magnetic field of } 3 \mathrm{~T} \text { for } 20 \text { min }\end{array}$ & $\begin{array}{l}\text { significant differences in microleakage between the } \\
\text { groups exposed to MRI and controls, whereas } \\
\text { differences in microleakage between } \\
\text { amalgam types were insignificant. }\end{array}$ & Yilmaz and Misirlioglu [30] \\
\hline MRI $(1.5 \mathrm{~T})$ & Microleakage of amalgam & $\begin{array}{l}63 \text { human freshly extracted premolars were } \\
\text { divided into } 3 \text { groups ( } 3 \text { different amalgams). } \\
\text { In each group, } 50 \% \text { of the samples were } \\
\text { exposed to MRI. }\end{array}$ & $\begin{array}{l}\text { Differences in microleakage within each group following } \\
\text { MRI were significant in the GS- } 80 \text { and Vivacap groups but } \\
\text { not in the Cinalux group. }\end{array}$ & Shahidi et al. [29] \\
\hline MRI $(1.5 \mathrm{~T})$ & Microleakage of amalgam & $\begin{array}{l}40 \text { teeth were randomly divided into four groups.. } \\
\text { The first and third groups were exposed to MRI. }\end{array}$ & $\begin{array}{l}\text { No significant differences of occlusal and gingival surface } \\
\text { microleakage after MRI exposure were observed. }\end{array}$ & Akgun et al. 2014 [29] \\
\hline Wi-Fi & Mercury release & $\begin{array}{l}20 \text { extracted teeth were randomly divided } \\
\text { into } 2 \text { groups of Wi-Fi exposure and control. }\end{array}$ & $\begin{array}{l}\text { A significant increase in mercury release was } \\
\text { observed in Wi-Fi exposed group. }\end{array}$ & Current study \\
\hline
\end{tabular}


habits and thermal effects [15, 44]. On the other hand some factors that may decrease the mercury release such as the liberation of corrosive products by contact of food and bacteria did not also interference with our findings.

\section{Conclusion}

To the best of our knowledge, this is the first study which assesses the effect of exposure to Wi-Fi signals on mercury release from amalgam restorations. We speculated that exposure to radiofrequency emitted from Wi-Fi devices may result in mercury release from amalgam restorations. Further in vitro and in vivo studies are necessary to prove this contention.

\section{Abbreviations}

CV ICP-MS, cold vapor inductively coupled plasma mass spectrometry; CVAAS, cold vapor atomic absorption spectrometry; CVAFS, cold vapor fluorescence spectrometry; EMF, electromagnetic fields; ET AAS, electrothermal atomic absorption spectrometry; ICP OES, inductively coupled plasma optical emission spectrometry; MRI, magnetic resonance imaging; SHF, super high frequency; UHF, ultra high frequency; Wi-Fi, wireless fidelity.

\section{Acknowledgement}

This study was supported by the Biomaterial Research center, School of Dentistry and lonizing and Non-ionizing Radiation Protection Research Center (INIRPRC), Shiraz University of Medical Sciences (SUMS), Shiraz, Iran. The authors would like to thank Dr. Sh. Hamedani (DDS, MSc) for his editorial assistance.

\section{Funding}

This study was funded by Shiraz University of Medical Sciences (SUMS). This research project received funding from SUMS to conduct the project. However, conception, design, acquisition of data and data analysis, interpretation and drafting of the manuscript were solely the responsibility of the authors. Moreover, the decision to submit the manuscript was solely the decision of the authors.

\section{Availability of data and materials}

The authors agree to make the raw data and materials described in their manuscript freely available to any scientist wishing to use them for noncommercial purposes (http://crrs.sums.ac.ir/fa/index.html).

\section{Authors' contributions \\ MP carried out the filling of the teeth and drafted the manuscript. SMJM participated in the design of the study and carried out the exposures and revised the manuscript. GM and MH performed the exposures and mercury measurements. Shoaleh Shahidi participated in the design of the study. All authors read and approved the final manuscript.}

\section{Competing interests}

The authors declare that they have no competing interests.

\section{Consent for publication}

Not applicable.

\section{Ethics approval and consent to participate}

This study was approved by the medical ethics committee of Shiraz University of Medical Sciences (No. 91-01-75).

\section{Author details}

'Department of Oral and Maxillofacial Radiology, School of Dentistry, Shiraz University of Medical Sciences, Shiraz, Iran. ${ }^{2}$ Medical Physics and Medical Engineering Department, School of Medicine, Shiraz University of Medical Sciences, Imam Hossein Square, 7134845794 Shiraz, Iran. ${ }^{3}$ Ionizing and
Non-ionizing Radiation Protection Research Center (INIRPRC), Shiraz University of Medical Sciences, Shiraz, Iran. ${ }^{4}$ Biomaterial Research Center, School of Dentistry, Shiraz University of Medical Sciences, Shiraz, Iran.

Received: 30 June 2015 Accepted: 1 July 2016

Published online: 13 July 2016

\section{References}

1. Clarkson T. The three modern faces of mercury. Environ Health Perspect. 2002;110 suppl 1:11-23. Find this article online.

2. Newman SM. Amalgam alternatives: what can compete? J Am Dent Assoc. 1991;122(8):67-71

3. Hamila NA, Oreby M, Al-nimer T, Hibishy H, Seleem M. Urinary Mercury Level, Neurobehavioral Performance And Some Biochemical Markers In Children with Amalgam Restorations. J Am Sci. 2013;9(12): 430-440.

4. Levy M, Schwartz S, Dijak M, Weber J-P, Tardif R, Rouah F. Childhood urine mercury excretion: dental amalgam and fish consumption as exposure factors. Environ Res. 2004;94(3):283-90.

5. Fung YK, Molvar MP. Toxicity of mercury from dental environment and from amalgam restorations. J Toxicol Clin Toxicol. 1992;30(1):49-61.

6. Guzzi G, Grandi M, Cattaneo C, Calza S, Minoia C, Ronchi A, Gatti A, Severi G. Dental amalgam and mercury levels in autopsy tissues: food for thought. Am J Forensic Med Pathol. 2006;27(1):42-5.

7. Fredin B. Mercury release from dental amalgam fillings. Int J Risk Safety Med. 1993;4(3):197-208.

8. Bharti R, Wadhwani KK, Tikku AP, Chandra A. Dental amalgam: An update. J Conserv Dent: JCD. 2010;13(4):204.

9. Mutter J. Is dental amalgam safe for humans? The opinion of the scientific committee of the European Commission. J Occup Med Toxicol. 2011;6(2). doi:10.1186/1745-6673-6-2.

10. Ozdabak HN, Karaoğlanoğlu S, Akgül N, Polat F, Seven N. The effects of amalgam restorations on plasma mercury levels and total antioxidant activity. Arch Oral Biol. 2008;53(12):1101-6.

11. Organization WH. Inorganic mercury-Environmental health criteria. Geneva, Switzerland: WHO; 1991. p. 118.

12. Gauba P, Shakeel M, Gaur S. Mercury Neurotoxicity: a review of case studies. Asian J Multidiscip Stud. 2015;3(1):9-16.

13. Clarkson TW, Magos L. The toxicology of mercury and its chemical compounds. Crit Rev Toxicol. 2006:36(8):609-62

14. Herman S. Industrial motor control. Boston, US: Cengage Learning Inc;; 2013

15. Al-Saleh I. Mercury $(\mathrm{Hg})$ burden in children: the impact of dental amalgam. Sci Total Environ. 2011:409(16):3003-15.

16. Sambucci M, Laudisi F, Nasta F, Pinto R, Lodato R, Altavista P, Lovisolo GA, Marino C, Pioli C. Prenatal exposure to non-ionizing radiation: effects of WiFi signals on pregnancy outcome, peripheral B-cell compartment and antibody production. Radiat Res. 2010;174(6a):732-40.

17. Lenton D. Speaking of Wi-Fi. IEE Rev. 2003;49(7):44-7.

18. Oni OM, Amuda DB, Gilbert CE. Effects of radiofrequency radiation from WiFi devices on human ejaculated semen. Int J Res Rev Appl Sci. 2011;19:292-4.

19. Markovà E, Hillert L, Malmgren L, Persson BR, Belyaev IY. Microwaves from GSM mobile telephones affect 53BP1 and $\mathrm{\gamma}$-H2AX foci in human lymphocytes from hypersensitive and healthy persons. Environ Health Perspect. 2005:1172-1177.

20. Mortazavi S, Rouintan M, Taeb S, Dehghan N, Ghaffarpanah A, Sadeghi Z, Ghafouri F. Human short-term exposure to electromagnetic fields emitted by mobile phones decreases computer-assisted visual reaction time. Acta Neurol Belg. 2012;112(2):171-5.

21. Mortazavi S, Vazife-Doost S, Yaghooti M, Mehdizadeh S, Rajaie-Far A. Occupational exposure of dentists to electromagnetic fields produced by magnetostrictive cavitrons alters the serum cortisol level. J Nat Sci Biol Med. 2012;3(1):60.

22. Mortazavi SMJ, Tavassoli A, Ranjbari F, Moammaiee P. Effects of laptop computers' electromagnetic field on sperm quality. J Reprod Infertil. 2010;11(4): 251-258.

23. Mortazavi SMJ, Shahram T, Dehghan N. Alterations of visual reaction time and short term memory in military radar personnel. Iran J Public Health. 2013;42(4):428.

24. Mortazavi S, Parsanezhad M, Kazempour M, Ghahramani P, Mortazavi A, Davari M. Male reproductive health under threat: Short term exposure to 
radiofrequency radiations emitted by common mobile jammers. J Hum Reprod Sci. 2013;6(2):124.

25. Müller-Miny H, Erber D, Möller H, Müller-Miny B, Bongartz G. Is there a hazard to health by mercury exposure from amalgam due to MRI? J Magn Reson Imaging. 1996;6(1):258-60.

26. Mortazavi G, Mortazavi SM. Increased Mercury Release from Dental Amalgam Restorations after Exposure to Electromagnetic Fields as a Potential Hazard for Hypersensitive People and Pregnant Women. Rev Environ Health. 2015;30(4):287-92.

27. Mortazavi SMJ, Daiee E, Yazdi A, Khiabani K, Kavousi A, Vazirinejad R, Behnejad B, Ghasemi M, Balali Mood M. Mercury release from dental amalgam restorations after magnetic resonance imaging and following mobile phone use. Pak J Biol Sci. 2008;1 1(8):1142-6.

28. Mortazavi SMJ, Neghab M, Anoosheh SMH, Bahaeddini N, Mortazavi G, Neghab P, Rajaeifard A. High-field MRI and Mercury release from dental amalgam fillings. Int J Occup Environ Med. 2014;5(2):101-5.

29. Shahidi SH, Bronoosh P, Alavi AA, Zamiri B, Sadeghi AR, Bagheri MH, Javadpour $\mathrm{S}$. Effect of magnetic resonance imaging on microleakage of amalgam restorations: an in vitro study. Dento maxillo Facial Radiol. 2009;38(7):470-4.

30. Yilmaz S, Misirlioglu M. The effect of 3 T MRI on microleakage of amalgam restorations. Dento maxillo Facial Radiol. 2013:42(8):20130072.

31. Mortazavi S, Neghab M, Anoosheh S, Bahaeddini N, Mortazavi G, Neghab P, Rajaeifard A. High-field MRI and mercury release from dental amalgam fillings. Int J Occup Environ Med. 2014;5(2 Apri):316-101-315.

32. Leopold K, Foulkes M, Worsfold P. Methods for the determination and speciation of mercury in natural waters-a review. Anal Chim Acta. 2010;663(2):127-38.

33. da Silva DG, Portugal LA, Serra AM, Ferreira SL, Cerdà V. Determination of mercury in rice by MSFIA and cold vapour atomic fluorescence spectrometry. Food Chem. 2013;137(1):159-63.

34. Matusiewicz H, Sturgeon RE. Chemical vapor generation with slurry sampling: a review of applications to atomic and mass spectrometry. Appl Spectrosc Rev. 2012;47(1):41-82

35. Gao Y, Shi Z, Long Z, Wu P, Zheng C, Hou X. Determination and speciation of mercury in environmental and biological samples by analytical atomic spectrometry. Microchem J. 2012;103:1-14.

36. Bendl RF, Madden JT, Regan AL, Fitzgerald N. Mercury determination by cold vapor atomic absorption spectrometry utilizing UV photoreduction. Talanta. 2006;68(4):1366-70.

37. Segade SR, Tyson JF. Determination of inorganic mercury and total mercury in biological and environmental samples by flow injection-cold vaporatomic absorption spectrometry using sodium borohydride as the sole reducing agent. Spectrochim Acta B At Spectrosc. 2003;58(5):797-807.

38. Ferracane J, Mafiana P, Cooper C, Okabe T. Time-dependent dissolution of amalgams into saline solution. J Dent Res. 1987;66(8):1331-5.

39. Avendaño C, Mata A, Sanchez Sarmiento CA, Doncel GF. Use of laptop computers connected to internet through Wi-Fi decreases human sperm motility and increases sperm DNA fragmentation. Fertil Steril. 2012;97(1):39-45. e32.

40. Mahmoudi R, Mortazavi SMJ, Safari S, Nikseresht M, Mozdarani H. Microwave Electromagnetic Radiations Emitted from Common Wi-Fi Routers Reduce Sperm Count and Motility. Iran J Radiat Res (IJRR). in press.

41. Use FMP. Mercury release from dental amalgam restorations after magnetic resonance imaging and following mobile phone use. Pak J Biol Sci. 2008;11(8):1142-6.

42. Kursun $\mathrm{S}$, Öztas B, Atas H, Tastekin M. Effects of X-rays and magnetic resonance imaging on mercury release from dental amalgam into artificial saliva. Oral Radiol. 2014;30(2):142-6.

43. Berglund A, Bergdahl J, Hansson MK. Influence of low frequency magnetic fields on the intra-oral release of mercury vapor from amalgam restorations. Eur J Oral Sci. 1998:106(2 Pt 1):671-4.

44. Soh G, Chew C, Lee A, Yeoh T. Thermal effect on the dissolution of mercury from two dental amalgams. J Oral Rehabil. 1991;18(2):179-83.

\section{Submit your next manuscript to BioMed Central and we will help you at every step:}

- We accept pre-submission inquiries

- Our selector tool helps you to find the most relevant journal

- We provide round the clock customer support

- Convenient online submission

- Thorough peer review

- Inclusion in PubMed and all major indexing services

- Maximum visibility for your research

Submit your manuscript at www.biomedcentral.com/submit
Biomed Central 